\title{
Article
}

\section{Pharmacokinetic Herb-Drug Interactions: Insight into Mechanisms and Consequences}

Oga, Enoche Florence, Sekine, Shuichi, Shitara, Yoshihisa and Horie, Toshiharu

Available at http://clok.uclan.ac.uk/14539/

Oga, Enoche Florence ORCID: 0000-0002-2661-0574, Sekine, Shuichi, Shitara, Yoshihisa and Horie, Toshiharu (2016) Pharmacokinetic Herb-Drug

Interactions: Insight into Mechanisms and Consequences. European Journal of Drug Metabolism and Pharmacokinetics, 41 (2). pp. 93-108. ISSN 0378-7966

It is advisable to refer to the publisher's version if you intend to cite from the work.

For more information about UCLan's research in this area go to

http://www.uclan.ac.uk/researchgroups/ and search for < name of research Group>.

For information about Research generally at UCLan please go to http://www.uclan.ac.uk/research/

All outputs in CLoK are protected by Intellectual Property Rights law, including Copyright law. Copyright, IPR and Moral Rights for the works on this site are retained by the individual authors and/or other copyright owners. Terms and conditions for use of this material are defined in the policies page.

\section{CLoK}

Central Lancashire online Knowledge www.clok.uclan.ac.uk

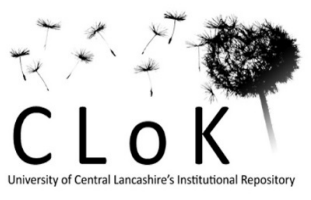


Pharmacokinetic herb-drug interactions: insight into mechanisms and consequences

Enoche F. Oga ${ }^{1}$, Shuichi Sekine ${ }^{2}$, Yoshihisa Shitara ${ }^{3}$ and Toshiharu Horie ${ }^{4}$

${ }^{1}$ School of Pharmacy \& Biomedical Sciences, University of Central Lancashire, Preston, United Kingdom

${ }^{2}$ Department of Biopharmaceutics, Chiba University, Chiba, Japan

${ }^{3}$ Pharmacokinetics Laboratory, Meiji Seika Pharma Co., Ltd, Yokohama, Japan

${ }^{4}$ Department of Biopharmaceutics and Molecular Toxicology, Teikyo Heisei University, Tokyo, Japan

To whom correspondence should be addressed:

Enoche Florence Oga, Ph.D.,

School of Pharmacy \& Biomedical Sciences,

University of Central Lancashire,

Preston, Lancashire.

PR1 2HE, United Kingdom.

Tel: +44 1772895842

E-mail: eoga@uclan.ac.uk 


\section{ABSTRACT}

Herbal medicines are currently in high demand, and their popularity is steadily increasing. Because of their perceived effectiveness, fewer side effects, and relatively low cost, they are being used for the management of numerous medical conditions. However, they are capable of affecting the pharmacokinetics and pharmacodynamics of co-administered conventional drugs. These interactions are particularly of clinically relevance when metabolizing enzymes and xenobiotic transporters, which are responsible for fate of many drugs, are induced or inhibited, sometimes resulting in unexpected outcomes.

The main focus of this article is an evidence for pharmacokinetic herb-drug interactions. A review of literature reporting herbal medicines, their effects and documented interactions with conventional drugs was conducted between January 2012 and June 2015 on research databases. Relevant studies were identified through searches of electronic databases, citations, reference lists, comprehensive pearl growing and handsearching related journals and conference proceedings. The relevant online databases (including PubMed, Cochrane database, Google Scholar and Web of Science) were utilised using online keyword searches, with searches limited by date to reports published from 1985 onwards.

This paper discusses the general use of herbal medicines in the management of several ailments, their concurrent use with conventional therapy, mechanisms underlying herb-drug interactions (HDIs) as well as the draw-backs of herbal remedy use. The authors also suggest means of surveillance and safety monitoring of herbal medicines. Contrary to popular belief that "herbal medicines are totally safe", we are of the view that 
they are capable of causing significant toxic effects and altered pharmaceutical outcomes when co-administered with conventional medicines. Due to the paucity of information as well as the sometimes conflicting reports on HDIs, much more research in this field is needed. The authors further suggest the need to standardize and better regulate herbal medicines in order to ensure their safety and efficacy, when used alone or in combination with conventional drugs.

\section{Keywords}

Cytochrome enzymes, drug transporters, herb-drug interactions, pharmacokinetics, toxicity

\section{Abbreviations}

ABC, ATP binding cassette; AUC, Area under the plasma concentration-time curve; BCRP, Breast cancer resistance protein; BSEP, Bile salt export pump; CAR, Constitutive androstane receptor; CYP, Cytochrome enzymes; DDI, Drug drug interactions; FMO, Flavin-containing mono-oxygenase; HDI, Herb drug interactions; HIV/AIDS, Human immunodeficiency virus and Acquired immune deficiency syndrome; MATE, Multidrug and toxic compound extrusion transporters; MRP, Multidrug-associated resistance proteins; OAT, Organic anion transporters; OATP, Organic anion transporting polypeptides; OCT, Organic cation transporters; PEPT, Peptide transporters; P-gp, Permeability glycoprotein; PXR, Pregnane X receptor; SLC, Solute carrier, UDP, Uridine dinucleotide phosphate; VDR, Vitamin D-binding receptor; WHO, World Health Organization

\section{Overview of herbal medicine use}


Herbal medicine comprises the use of plant parts for medicinal purposes. Unlike conventional drugs, most herbal medicines are a complex mixture of chemical constituents whose bioactive components in many instances are yet to be fully characterized, but have been reported to be medicinally efficacious [1]. There is a long history of the use of these phytomedicines, with herbalism having a long tradition of use outside of conventional medicine. Their use has become more established as improvements in analysis and quality control as well as advances in clinical research has shown their value in treating and preventing disease [2]. In some developing countries, up to $80 \%$ of the indigenous populace are known to depend on traditional systems of medicine and medicinal plants as their primary source of healthcare [3, 4]. This occurrence is not significantly different across the globe. For instance, reports show that over $70 \%$ of German physicians prescribe herbal medicines and over $75 \%$ of the German populace have used complementary or natural medicine [5]. In countries like the United States, an increase in their use has been reported due to dissatisfaction with the cost of prescription medications, combined with an interest in returning to natural or organic medicines [6]. In Japan, about 148 kinds of Japanese herbal medicines (Kampo medicines) have been approved and are enlisted on the National Health Insurance Drug Tariff. These medicines are reportedly prescribed by 72-78\% of Japanese physicians [7, 8]. These plant-based medicines are believed to be increasingly utilized because of their low cost, perceived safety, efficacy and lower incidence of adverse effects when compared to orthodox medicines. While their use is on the increase in some countries, stringent regulatory requirements in other countries make it difficult to register herbal medicines, therefore their reported limited use [9]. In the United Kingdom, herbal medicines have been recognized as substances that pose 
particular challenges for public health and effective regulation is being sought which would safeguard the public. To this end, there have been deliberations on the need for statutory regulation of UK herbal medicine and its practitioners [10, 11].. It is worthy to note that approximately $30-50 \%$ of conventional medicines in use evolved from natural products from where they are synthesized as pharmaceutical preparations [12-14]. In particular are the medicines Catharanthus roseus (vincristine), Atropa belladonna (atropine), Cinchona sp. (quinine), Cephaelis ipecacuanha (emetine), Digitalis purpurea (digitoxin and digoxin), Ephedra sinica (ephedrine), (Artemisia annua (artemisinin), Rauwolfia serpentine (reserpine), Podophyllum peltatum (etoposide) among several others.

\section{Mechanisms of herb-drug interactions}

Similar to conventional pharmaceutical products, pharmacokinetic and pharmacodynamic alterations are the two mechanistic pathways through which herb-drug interactions (HDIs) occur, resulting in null, beneficial or toxic responses (Figure 1). In addition to the cytochrome enzymes, membrane transporters are known play an important role in the modulation of absorption, distribution, metabolism and excretion of drugs [15]. These HDIs arise from changes in the function and expression of transporters or enzymes that mediate the absorption and elimination of drugs in the small intestine, kidney and liver [16].

\subsection{Enzyme-mediated HDIs}

One of the most important causes of clinically-relevant HDIs is the inhibition or induction of the activity of cytochrome P450, a superfamily of enzymes catalyzing an extremely diverse and often complex reactions in the metabolism of numerous drugs, phytomedicines and xenobiotics. P450s are the main enzymes involved in drug 
metabolism, with the majority of drugs interacting with the CYP 3A isoform $[17,18]$. For instance, several intestinal CYP 3A inhibitors (including the triterpenes; maslinic acid, corosolic acid, and ursolic acid) have been isolated from Vaccinium macrocarpon (cranberry) [19]. Cranberry is now commonly taken as a treatment for urinary tract infections due to a group of proanthocyanidins which exhibit bacterial anti-adhesion activity against both antibiotic susceptible and resistant strains of uropathogenic Escherichia coli bacteria [19, 20]. Another study revealed that cranberry juice inhibits the CYP3A-mediated metabolism of nifedipine altering its pharmacokinetics by increasing the concentration of nifedipine in rat plasma [21]. The study demonstrated that the oxidative activities of nifedipine in rat intestinal and human hepatic microsomes were inhibited after pre-incubation with cranberry juice [21]. However, a clinical study in 10 healthy volunteers involving the CYP3A probe substrate; midazolam and a cranberry juice product suggested that interaction was unlikely [22]. However, in a more recent study that utilized a systematic approach, from in vitro assay (Caco-2 cell and human intestinal microsomes) to a clinical study in 16 healthy volunteers, it was observed that a cranberry juice product revealed a pharmacokinetic interaction with midazolam [23]. The difference in the finding of these studies suggests the importance of utilizing clinical regimens and taking into consideration the interbrand variation of natural products in the design of pharmacokinetic studies. Similarly, the widely used herbal remedy, Echinacea purpurea (Echinacea) has been reported to significantly induce CYP 3A [24]. It has been shown to selectively modulate the catalytic activity of CYP3A at hepatic and intestinal sites, suggesting that CYP 3A substrates with relatively high bioavailability may be more susceptible to Echinacea-mediated interactions [25, 
26]. As CYP 3A is the main drug metabolizing enzyme, the potential of HDIs occurring with Echinacea purpurea may be high.

\subsection{Transporter-mediated HDIs}

Although most studies have focused on cytochrome-based drug interactions, the influence of transporters as a mechanism for HDIs is increasingly being documented, as it has been revealed that they can play an important role in modulating drug absorption, distribution, metabolism and elimination. Figure 2 illustrates the distribution of relevant transporters in the main organs responsible for drug disposition. Xenobiotic transporters are generally categorized into the ATP binding cassette (ABC) and solute carrier (SLC) superfamilies.

\subsubsection{ATP Binding Cassette-based HDIs}

ABC transporters function as barrier proteins extruding toxins and xenobiotics out of cells. They include p-glycoprotein (P-gp), breast cancer resistance protein (BCRP), bile salt export pump (BSEP) as well as several multidrug-associated resistance proteins (MRPs). They are commonly expressed on barrier epithelia where they mediate transport across cell membranes [15]. These transporters are significant determinants of the pharmacokinetics, efficacy and toxicity of xenobiotics (including phytomedicines) and co-administered drugs may inactivate, inhibit or induce these transporters. Of all the transporter-mediated HDIs, P-gp based interactions are the most studied. There are reports on the modulation of P-gp by herbs such as Hypericum perforatum (St. John's wort), Vernonia amygdalina (Bitter leaf), Tapinanthus sessilifolius (African mistletoe), Coptis chinensis (Chinese goldthread), Ginkgo biloba (Maidenhair tree), Piper nigrum (Black pepper) and Glycorrhiza glabra (Licorice) [16, 27, 28].

\subsubsection{Solute Carrier-based HDIs}


The solute carrier (SLC) transporters mainly comprise of uptake transporters including the organic anion transporting polypeptides (OATPs), organic cation transporters (OCTs), organic anion transporters (OATs), peptide transporters (PEPT) and multidrug and toxic compound extrusion transporters (MATE) [15]. These SLC transporters are known to facilitate absorption of phytomedicines and xenobiotics into the systemic circulation. Because transporters are mainly expressed in the intestinal epithelial cells and organs of elimination (kidney proximal tubules and liver hepatocytes), they can significantly influence the disposition of herbal medicines [29]. Fewer reports investigate the influence of SLC-mediated herb-drug interactions when compared to ABC transporters, where majority of the studies examine the interaction with P-gp [30]. However, several interesting drug-food interactions with fruit juices, involving uptake transporters have been reported [31, 32]. For instance, grapefruit juice inhibition of OATP resulted in reduced blood levels of fexofenadine, celiprolol, talinolol and acebutolol [33]. On the contrary, concurrent intake of grapefruit juice has been shown to increase the in vivo plasma concentrations of many drugs. This has been attributed to various factors, including, the inhibition of P-gp and an inhibition of intestinal CYP3A4, resulting in an increase in the fraction of drug absorbed [34]. Other clinical reports on SLC transporters include a study in healthy volunteers on baicalin from Radix scutellariae (Baikal skullcap), which showed a reduction in the plasma concentration of co-administered rosuvastatin as a result of OATP modulation [35]. In the study, the observed decrease in the plasma concentration of rosuvastatin in the presence of baicalin was thought to be partially mediated by baicalin's induction of hepatic rosuvastatin uptake through OATP1B1 [35]. A study in rats reported that the pharmacokinetic disposition of salvianolic acid B was altered by rifampicin due to the 
inhibition of Oatp-mediated influx [36]. Salvianolic acid B is one of the most bioactive components of Salvia miltiorrhiza (Red sage), a traditional Chinese herbal medicine that is commonly used for prevention and treatment of cerebrovascular and cardiovascular disorders. Likewise, herbs modulating OAT1, a transporter actively involved in renal active secretion have been reported [37]. Among several Chinese herbal medicines examined in the study, two exhibited significant inhibitions on hOAT1-mediated $\left[{ }^{3} \mathrm{H}\right]$-p-amino hippuric acid uptake in vitro as well as p-amino hippuric acid clearance and net secretion in vivo [37].

\subsection{Dual enzyme- and transporter-mediated HDIs}

Some phytomedicines are known to influence both transporter and cytochrome enzyme function. P-gp and CYP 3A4 both constitute a highly efficient barrier for many orally absorbed drugs with a wide overlap in their substrates [38]. Rhodiola rosea (Golden root), a herbal medicine used in the management of depression has shown potent inhibition of both P-gp and CYP 3A4 [39]. Also, St. John's wort (Hypericum perforatum), one of the most widely used herbal medicines with several medicinal effects including its recognized antidepressant properties, induces both CYP 3A and the efflux transporter; P-gp [40]. A recent study revealed that quercetin and rutin which are popular herbal flavonoids, induced the functions of both P-gP and CYP3A4 by decreasing the bioavailability of co-administered cyclosporin [41]. These alterations on normal P-gp efflux and CYP activity has an impact on the pharmacokinetic disposition

of CYP 3A and P-gp substrate drugs when co-administered leading to changes, including lower efficacy and/or the emergence of toxicity [42].

\subsection{Influence on transcriptional regulators}


Several CYPs and transporters that influence drug disposition can be induced by xenobiotics and herbs [43]. The nuclear receptors; pregnane $\mathrm{X}$ receptor (PXR) and constitutive androstane receptor (CAR) which are present in the small intestine and liver have emerged as transcriptional regulators of cytochrome P450 isoenzymes (especially CYP 3A, -2B6, -2C8, -2C9 and -2C19) and drug transporters: P-gp, MRP2 and OATP [44, 45]. Besides the various xenobiotics that have been reported to activate PXR, herbals including St. John's Wort are known to potently induce it [46]. These nuclear receptors have also been reported to enhance the expression of phase II conjugating enzymes like UDP-glucuronosyl transferase, sulfotransferase and glutathione-S-transferase enzymes [47, 48]. As a result of an increased induction of these nuclear receptors, there is an enhanced expression of P-gP and CYP enzymes which are likely to reduce the rate of absorption and increase the rate of elimination of drug substrates.

\section{Herbal medicine use and interactions with conventional drugs}

Several evidence-based studies on clinically relevant HDIs have been documented.

Table 1 summarizes some clinically significant herb-drug interactions.

\subsection{Cancer}

Because of the high global incidence of cancer, the use of herbal medicines by cancer patients is quite common with an increasing number of cancer patients making use of complementary and alternative medicines in combination with their conventional chemotherapeutic treatment [49]. Among cancer patients in general, between 7- $48 \%$ have reported taking herbal medicines [50]. These herbal medicines are used by cancer patients with the belief that they are capable of killing tumor cells, improving cancer-related symptoms as well as reducing the adverse drug effects posed by the 
therapy [51]. However, in order to appropriately integrate herbal medicine use into conventional cancer therapy, pharmacological and clinical studies must be carried out on these herbals, with relevant monitoring for the emergence of adverse effects [52]. This is of particular importance as several chemotherapeutic agents are known to have considerable inter-individual pharmacokinetic variability which coupled with their narrow therapeutic index, may pose a higher risk for the occurrence of toxic HDIs. For instance, St John's wort has been reported to induce the metabolism of imatinib, an oncolytic used in the management of chronic myelogenous leukemia and gastrointestinal stromal tumors. These studies showed an alteration in the pharmacokinetics of imatinib when co-administered with St John's wort due to an induction of CYP 3A $[53,54]$. This induction of CYP isoenzymes and drug transporters would often lead to therapeutic failure as a result of a lower plasma level of the anticancer drugs [49]. Likewise, a pharmacodynamic interaction involving irinotecan (a potent anticancer drug for the management of advanced colon cancer), which may cause severe diarrhea as an adverse effect has been reported to have worsened diarrhea on co-administration with St John's wort through down-regulation of intestinal pro-inflammatory cytokines and inhibition of intestinal epithelial apoptosis [55]. In another study, the metabolism and toxicity of irinotecan was altered on co-administration with St John's wort with a compromise in overall antitumor activity [56]. Grapefruit juice intake has been reported to alter the pharmacokinetics of the cytotoxic drug; etoposide, with a clinical study revealing a $26.2 \%$ decrease in the AUC of etoposide after oral administration. It was postulated that the alteration of intestinal P-gp mediated transport was a possible explanation for the observed effect [57]. Several in vitro studies have been reported with pointers to the possibility of relevant herb-drug 
interactions. For example, Ginsenoside Rh2 from Panax ginseng significantly enhanced the cytotoxicity of daunomycin and vinblastine in adriamycin resistant P388 leukaemia cells [58]. Another pharmacologically active constituent from Panax ginseng, Ginsenoside Rg3 inhibited the efflux of vinblastine and reversed resistance to doxorubicin and vincristine in drug resistant KBV20C cells [59]. Competition of Ginsenoside Rg3 for binding to P-gp was demonstrated as the mechanism for the inhibition of drug efflux. The study showed that ginsenoside Rg3 was an effective modulator in restoring the sensitivity of resistant cells to doxorubicin, vincristine, etoposide and colchicine in human P-gp MDR cells at concentrations of 5 to $40 \mu \mathrm{M}$ [59]. Although no clinical report on drug interaction studies involving ginseng and P-gp substrates are known, these in vitro studies on its P-gp blockade role may point to its beneficial function as a natural multidrug resistance reversal agent [60].

Also on a positive note, because of the hepatotoxicity caused by some conventional anticancer drugs, herbal medicines including; Punica granatum (pomegranate), Phyllanthus emblica (Indian gooseberry), Mangifera indica (mango), Acacia catechu (Black cutch) and Camellia sinensis (Tea) have been used for their hepatoprotective and antioxidant property when hepatotoxic chemotherapeutic agents are utilized [61]. Other herbal medicines used frequently by cancer patients include Zingiber officinale (ginger), Ginkgo biloba (ginkgo), Piper methysticum (kava-kava), quercetin (from several plants and also honey), Panax sp (ginseng), Curcuma longa (curcumin), Viscum album (European mistletoe), beta-carotene (especially from Daucus carota), Glycyrrhiza glabra( licorice), Astragalus membranaceus (astragalus), Viscum album (mistletoe), Echinacea sp. (echinacea), Berberis aristata (Indian barberry) and Allium sativum (garlic). These medications are perceived to be non-toxic, alleviate the symptoms 
of cancer, boost the immune system, manage the adverse effects of chemotherapeutics, or may even tackle the cancer itself $[27,62]$. On the whole, further research is required to prevent therapeutic failure and toxicity in cancer patients when herbal medicines are concurrently taken with conventional medicines. This would aid in establishing guidelines for their concomitant use.

\subsection{HIV/AIDS}

Around the world, the HIV epidemic rages on, emerging the greatest challenge to global health. However, AIDS-related deaths are decreasing largely due to increased access to treatment. Herbal medicines are widely used by HIV patients to complement conventional therapy, with an increasing number of studies investigating their use in HIV management [63]. Common herbal medicines used during HIV management include Allium Sativum (garlic), Eucalyptus globulus (Blue gum), Aloe vera, Trigonostema xyphophylloides, Vatica astrotricha, Vernonia amygdalina (Bitterleaf), Lippia javanica (Fever tree), Bidens pilosa (Blackjack), Peltoforum africanum (Weeping wattle), Hypoxis hemerocallidea (African star grass) and Moringa oleifera (Drumstick tree) $[16,64,65]$. However, it is of importance to thoroughly investigate the potential alterations in pharmacokinetic and toxicological profiles when they are co-administered with conventional medicines as their concurrent use has resulted in beneficial and/or detrimental effects. For instance, an in vitro study revealed that Sutherlandia frutescens (Cancer bush) inhibited the metabolism of atazanavir in human liver microsomes, and may have important implications on the absorption and metabolism and the overall oral bioavailability of atazanavir [66]. Also the HIV protease inhibitor; ritonavir on co-administration with some herbal components has been shown to modulate both P-gp and CYP 3A4. In particular, the herbal constituents; 
kaempferol and quercetin (from several plants), hypericin (from Hypericum perforatum) and allicin (from Allium sativum) have been shown to inhibit the in vitro efflux and CYP3A4-mediated metabolism of xenobiotics and may interact with HIV antiretrovirals that are P-gp or CYP 3A4 substrates, such as ritonavir [67]. Also, a clinical study in healthy volunteers demonstrated that St. John's wort potently altered the pharmacokinetics of indinavir (a protease inhibitor and a known CYP450 substrate) via induction of CYP 3A by St. John's wort. As illustrated in Figure 3, the study revealed a large reduction in indinavir concentrations by concomitant St John's wort. This finding has important clinical implications for HIV-infected patients receiving the two agents since low plasma concentrations of protease inhibitors are a cause of antiretroviral resistance and treatment failure [68]. Garlic is another herbal remedy commonly utilized by HIV/AIDS patients. Although some studies have shown that garlic has the potential to induce CYP isoenzymes consequently reducing the effectiveness of antiretroviral drugs, in vitro assessments of its effect on CYP450 are conflicting [69, 70]. In a clinical study, garlic was shown to reduce the plasma pharmacokinetic concentrations of saquinavir by altering CYP3A4 isoform of the CYP450 enzyme system, the isozyme through which saquinavir is metabolized, recommending patient caution on concomitant administration [71]. Another study in healthy volunteers examining the effect of an odourless garlic product indicated an insignificant reduction in the AUC and plasma concentrations of ritonavir following short-term garlic consumption [72]. This is thought to arise from transitory induction followed by inhibition on the various drug disposition pathways of ritonavir especially as the treatment duration of garlic (twice daily for 4 days) was too short to observe a significant change in ritonavir plasma levels [72]. This informs the need for caution, 
especially if large quantities of raw or processed garlic are concomitantly taken with any protease inhibitor. Another study in healthy human subjects indicated a significant increase in bioavailability and maximum plasma concentration of nevirapine following 6 days of piperine intake [73]. Piperine is a major component of Piper nigrum and Piper longum (black pepper and long pepper respectively) and has been reported to inhibit drug-metabolizing enzymes and increase the plasma concentrations of several drugs, including P-gp substrates [74].

\subsection{Malaria}

Malaria is an important global public health issue with high morbidity and mortality rates. Majority of malarial endemic regions are from the world's developing economies. As a result of the relatively high costs for conventional antimalarials, many patients are known to take herbal medicines for its prevention and treatment [75]. Herbal medicines commonly used in the management of malaria include Vernonia amygdalina (Bitterleaf), Piper longum (Long pepper), Tapinanthus sessilifolius (African mistletoe), leaves of Carica papaya (Pawpaw), leaves and bark of Azadiractha indica (Neem) and rhizomes of Curcuma longa (turmeric) [76]. Sometimes these herbs are used alone or in combination with orthodox medicines. A study based on an in vitro (Caco-2 cell), ex vivo (Ussing chamber) and an in vivo rat model revealed that extracts of Vernonia amygdalina, Tapinanthus sessilifolius and Carica papaya which are herbals commonly used in traditional malaria, cancer and diabetes therapy inhibited P-gp mediated digoxin transport $[28,77]$. Findings from that study suggested that caution should be observed when those herbs are concomitantly used with P-gp substrate drugs as they may enhance their absorptive transport [28]. Frequently, antagonistic effects have been 
reported on co-administration of herbals and orthodox medicines. For instance, although the leaves of Carica papaya (Pawpaw) are known to exhibit antimalarial effect, the antagonistic antimalarial properties when used in combination with artesunic acid in Plasmodium berghei-infected mice has been reported [78]. In the study, the extracts of Carica papaya when solely administered had good antimalarial activity. In a similar study, the influence of Eurycoma longifolia extract (Commonly known as Tongkat ali; a herbal remedy commonly used in malaria therapy) was investigated on co-administration with artemisinin (WHO's recommended first-line antimalarial) in experimental mice. Findings from that study revealed the suppression of parasitemia in Plasmodium yoelii-infected mice. This is suggestive of a promising, potential antimalarial candidate by both oral and subcutaneous routes [79]. Similar synergistic herb-drug interactions involving goniothalamin (Goniothalamus scortechinii)-chloroquine, Vernonia amygdalina - chloroquine and curcumin (isolated from Curcuma longa) - artemisinin combinations have been documented with the suggestion that they be considered for future trials in the search for malaria combination therapy [80-82]. Also, herbs can be combined for their additive effect as shown by the mixture of a Khaya ivorensis (African mahogany) -Alstonia boonei (English alstonia) extract mixture as an antimalarial prophylactic remedy [83].

\subsection{Liver diseases}

Hepatic disorders (including alcoholic liver disease, hepatitis, cirrhosis and steatosis) are still a cause for global concern [84]. Unfortunately, several orthodox drugs used in the management of liver diseases are inadequate and sometimes can have serious side effects. However, herbal medicines have been used in the treatment of liver diseases since ancient times. Silybum marianum (milk thistle) is a widely used herbal 
remedy especially for the management of liver and gallbladder disorders [85]. Although preclinical evidence strongly supports its use as a hepatoprotectant, further well-designed clinical trials may be necessary to confirm this [86]. In-depth research has been conducted on its most active component- silymarin, a flavonoid complex. Silymarin and its active constituent, silybin, are believed to act as antioxidants, scavenging free radicals and inhibiting lipid peroxidation, thus finding use in chronic liver disorders [87, 88]. It is believed to be safe and well-tolerated, with very minor side effects reported when taken within the recommended dose range (gastrointestinal upset, mild laxative effect and rare allergic reaction). Because of its vast use, significant work has been carried out, examining the potential for herb-drug interactions. In a study by Gurley et al. (2006), [89] insignificant changes in the disposition of digoxin were observed on co-administration with silymarin, posing no clinically significant risk for P-gp-mediated herb-drug interactions. On the other hand, a study has shown that silybin A and silybin B at clinically relevant concentrations inhibit CYP 2C9-mediated metabolism of warfarin [90]. This HDI needs to be further evaluated because of the narrow therapeutic index of warfarin. In addition, there are several reports on the hepatoprotective function of glycyrrhizin (a major constituent of licorice). Besides inhibiting liver cell injury caused by many chemicals, it is also used in the treatment of chronic hepatitis and cirrhosis [91]. Glycyrrhizin has been shown to be a strong inhibitor of 11- $\beta$-hydroxysteroid dehydrogenase (the enzyme responsible for catalysing the conversion of cortisol to the inactive steroid cortisone) and is thought to alter the pharmacokinetics of prednisolone by inhibiting its metabolism. In one study, oral glycyrrhizin increased the plasma prednisolone concentrations in six healthy men [92]. 


\subsection{Asthma and Allergic diseases}

There are several reports on the use of herbal medicines in the treatment and management of asthma and allergic diseases (including allergic rhinitis, food allergy, and atopic dermatitis), which affect a high percentage of the population. Some of these phytomedicines are used alone, while some others are used in combination with conventional medicines. Corticosteroids are known to form a key component in the management of asthma and allergy. A study investigated the interaction potential of cortisol on concomitant administration with Glycyrrhiza glabra (licorice) and grapefruit juice. The findings showed significantly increased cortisol AUC and mean serum concentrations following the intake of licorice and grapefruit juice. Co-administration with grapefruit juice gave rise to a more complete intestinal absorption of cortisol during the first hours, indicative that interactions between various constituents and P-gp in the intestinal walls are implicated [93]. One study examined the relationship between the use of herbal medicines and adherence to inhaled corticosteroids. It was revealed that utilizing herbal medicines was associated with lower adherence to inhaled corticosteroids and poor outcomes among asthmatic patients probably due to patients worry over the adverse effects of the corticosteroids [94]. Petasites hybridus (Butterbur), a herbal remedy with antihistamine and anti-leukotriene activity conferred complementary anti-inflammatory activity in asthmatic patients who were receiving inhaled corticosteroids suggesting the potential benefit in asthma management [95]. Although theophylline is commonly utilized in asthma therapy, its use complicated by its interaction with several other drugs and its narrow therapeutic index. For instance in a study, its concomitant administration with St John's wort has resulted in reduced plasma concentration of theophylline. [96]. However, in another clinical study in health 
Japanese male volunteers, no significant alteration in the plasma pharmacokinetics of theophylline was observed when coadministered with St John's wort [97]. Likewise there are reports on herb-drug interactions involving fexofenadine, a well known P-gp substrate probe which is commonly used in the management of allergy. A clinical study in healthy volunteers indicated a significant increase in the maximum plasma concentration of fexofenadine and a significant decrease in its oral clearance following the administration of a single dose of St John's wort. In this study, no change in the half-life or renal clearance was observed [98]. This observation was also confirmed by another clinical study in healthy volunteers which demonstrated that pretreatment with St John's wort significantly enhanced the oral clearance of fexofenadine by 1.6-fold. Here also, no alteration in the half-life was observed. The authors suggested the predominant inductive effect of St John's wort on P-gp in the intestinal epithelium, which consequently caused a decrease in the absorbed fraction of oral fexofenadine [99]. As inhibition and induction of P-gp may significantly influence drug disposition, caution may need to be exercised in cases of their co-administration.

\subsection{Depression}

Several herbs have been used in the management of depression. Of particular note is Hypericum perforatum (St. John's wort) that has gained widespread popularity as "nature's Prozac". It has been used for centuries as a natural remedy for the treatment of a number of diseases [100]. Some clinical studies have provided evidence that it is as effective as conventional antidepressants. Although the anti-depressive mechanism is not fully understood, its therapeutic effects have been confirmed in several studies when compared with placebo or standard antidepressant agents [101]. Even though it is widely obtained as an over-the-counter remedy, knowledge about the pharmacokinetics 
of ingredients and drug interactions of St John's wort is not commensurate. Because of its ability to induce CYP 3A4/P-gp, there are some reports on its interaction with other CYP 3A/P-gp substrates leading to pharmacokinetic interaction with drugs known to have narrow therapeutic windows (E.g. Digoxin), to which therapeutic drug monitoring may be necessary [102]. Because several drugs are co-substrates of CYP 3A and P-gp, their disposition is markedly affected by concomitant administration of St John's wort through an activation of nuclear receptors, resulting in enhanced metabolism and efflux transport of the co-administered substrate drug to different extents depending on the relative contributions of CYP 3A and P-gp. For instance a study reported that the extent of induction measured by oral clearance was different with CYP3A activity (midazolam; which is solely metabolized by CYP 3A), which showed more increase than P-gp function (fexofenadine; a non-metabolized drug), whereas with cyclosporine (CYP 3A and P-gp are both importantly involved in its disposition), the change in oral clearance appeared to be more closely associated with the increase in MDR1 than with CYP 3A [99]. In general, most of these studies support the need for caution as well as stricter regulations of herbal medicines for safer drug therapy in medicine [103]. Panax ginseng is a widely used herbal medicine, notably used for its antidepressant effect. A study investigated the influence of Panax ginseng on CYP3A function using the probe midazolam as a substrate probe [104]. Comparison of pharmacokinetic parameter values of midazolam was calculated and compared before and following the administration of Panax ginseng. As illustrated in Figure 4, the findings revealed significant reduction for midazolam area under the concentration-time curve from zero to infinity, half-life and maximum concentration [104]. Also, American ginseng (Panax quinquefolius) reportedly reduces the effect of warfarin in healthy patients. This was observed in a 
clinical study in healthy volunteers following a ginseng consumption for 2 weeks in which changes in the international normalized ratio, AUC, peak plasma warfarin level, and warfarin AUC were found to be statistically significantly greater in the group [105]. Here, the effect was postulated to be as a result of the inductive effect of ginseng on the hepatic drug metabolizing enzyme system, as warfarin is known to be metabolized by the CYP system. Green tea (from Camelia sinesis) is a popular beverage and dietary supplement with some reported interactions with conventional medicines. A study in healthy subjects examined its interaction potential with buspirone (a CYP3A4 substrate). The extract containing $800 \mathrm{~g}$ epigallocatechin gallate was administered daily for 4 weeks to and was shown to significantly increase the bioavailability of buspirone [106]. Of note however is the fact that this cytochrome enzyme inhibition is unlikely to be of

clinical relevance [106]. Another human study further revealed that a decaffeinated extract of green tea did not alter the pharmacokinetics of either dextromethorphan or alprazolam indicating the improbability of green tea to alter the disposition of CYP2D6 or CYP3A4 substrates [107].

\subsection{Other conditions}

Herbal medicines are also widely used in the management colds, infections and inflammation. For instance, echinacea is commonly used for the treatment of the common cold, coughs, bronchitis, influenza, and inflammation of the mouth and pharynx and is one of the most sold herbal medicines in use and is reportedly consumed by $10 \%$ to $20 \%$ of herbal users [25]. Because of its immuno-stimulatory effect, it is also commonly used for HIV and upper respiratory tract infections [108, 109]. In a study investigating the influence of Echinacea purpurea on the in vivo activity of CYP 
isozymes (including CYP 3A4), after oral and intravenous midazolam administration, modulation of the catalytic activity of CYP 3A4 at both hepatic and intestinal sites were reported. Inhibition of intestinal CYP 3A4 activity was observed, with potent increase in midazolam's oral bioavailability as well as significant enhancement of midazolam's systemic clearance by inducing hepatic CYP 3A . In addition, the study advises the exercise of caution when it is co-administered with drugs that are dependent on CYP 3A or CYP 1A2 for their elimination [25].

Similarly, studies investigating interactions of Ginkgo biloba (Maidenhair tree)- a herbal remedy commonly used for memory enhancement, have been reported. For instance, a human study revealed a significant increase in the bioavailability and peak plasma concentration of talinolol as a result of P-gp efflux inhibition, following long-term administration of ginkgo [110, 111]. This effect was suggested to be as a result of the P-gp inhibitory effect of some ginkgo flavonol constituents, including quercetin, kaempferol, and isorhamnetin, which have been documented [112]. In another study, the effect of the extract of Ginkgo biloba on midazolam (CYP 3A4 substrate) and tolbutamide (CYP 2C9 substrate) was investigated [113]. There, the AUC of tolbutamide following ginkgo intake was significantly reduced. Conversely, the AUC of midazolam was significantly enhanced, while its oral clearance was decreased. However, another study reported the intestinal induction of CYP 3A4 following midazolam administration to healthy humans. After administration for 4 weeks, the bioavailability and maximum plasma concentration of midazolam significantly reduced with no change in the half-life suggestive of intestinal, but not hepatic, induction [113]. Another clinical study investigated the intake of the same dose of Ginkgo biloba extract after 2 weeks administration in combination with lopinavir, fexofenadine and 
midazolam [114]. The CYP3A4 inductive effect of ginkgo was indicated by a significant decrease in the AUC and maximum plasma concentration of midazolam. However, neither lopinavir nor ritonavir pharmacokinetic parameter values were significantly altered. This is likely due to ritonavir's more potent inhibition of CYP3A4. It was therefore suggested that the Ginkgo biloba extract may unlikely reduce the exposure of ritonavir-boosted protease inhibitors, while concentrations of un-boosted protease inhibitors may be affected [114].

\section{Draw-backs, surveillance and safety monitoring of herbal medicines}

Despite the fact that herbal medicines are widely used, the safety and efficacy profile of several of them are in doubt and unproven. Moreover, many consumers misinterpret the natural origin of herbal medicines as a sign of safety, without appreciating that herbal ingredients can cause serious adverse effects [115]. A major concern regarding the use of herbal medicines is their safety and toxicity profile. They may pose harm to patients under different circumstances through idiosyncratic or allergic reactions or the risk of herb-drug interaction occurring when taken concomitantly with conventional medicine. Because rigorous testing and regulatory agency approval is not routinely considered for many herbal medicines, they may be prone to easy adulteration or contamination, thus harmful. World over, several instances of toxicity have been reported on use of herbal medicines. Of significance is the development of kidney failure by several women in Belgium after taking slimming pills containing the herb Aristolochic fangchi. This further resulted in transitional cell carcinoma in some of these patients [116]. In addition, standardization of herbal medicines sometimes becomes challenging as their chemical makeup differs depending on the part of the plant used, growing conditions, periods of 
harvest as well as the storage conditions. Combination products composed of multiple natural products complicate matters further. In using herbal medicines, standardization, regulation and the scientific proof of patients' safety are of paramount importance, especially in the development phase [117]. However, this is not the case in many instances and has resulted in the emergence of toxic responses.

Although the use of herbal products is rapidly increasing, there are only few national surveillance systems monitoring and evaluating adverse reactions associated with their use [118]. In order to identify and assess the possible risks associated with herbal medicine use, pharmacovigilance studies are essential. For this, the establishment of pharmacovigilance centres would play a significant role in promoting awareness of herbal medicine safety and the need to report the observance of adverse drug reactions [119]. Pharmacovigilance encompasses the totality of monitoring drug safety including identifying plausible adverse drug interactions, assessing risks and benefits as well as conveying concerns over drug safety [120]. It is essential to regulate herbal medicine use as well as ensure appropriate quality control measures including quality specification, good manufacturing practices for herbal medicines, labeling and licensing schemes for manufacturing, imports and marketing should be enforced [121]. Also of importance is the need to extend knowledge on drug safety rather than the general approach of demonstrating toxicity. With an increased awareness and an increasing number of the populace utilizing herbal medicines, more and more toxicological assessments need to be being conducted. This is expected to include an investigation into the potential for genotoxicity, reproductive toxicity, hepatotoxicity, nephrotoxicity and neurotoxicity of the phytomedicines [122, 123]. There are recommendations concerning the need to strengthen expertise in toxicology as well as determining newer 
approaches towards solving the present toxicological issues [124]. For example, the Caenorhabiditis elegans model has been proven to be a reliable and invaluable tool in toxicological assessments especially with respect to neurotoxic evaluations. In addition to its sharing a high sequence identity with several human genes as well as its anatomical and physiological characteristics, its genome has been fully sequenced and the nervous system has been extensively studied thereby making it of immense benefit in toxicological assessments [125].

\section{Conclusion}

The use of herbal medicines is increasing, possibly due to their widespread promotion in the media as well as unsubstantiated health care claims. Although herbal medicines are beneficial, despite popular belief, they are not completely harmless and HDIs may occur on concomitant use with conventional drugs, but many possibly go unnoticed due to various factors. It is safer to view them as unrefined pharmaceuticals, capable of producing physiologic change, for better or worse.

Most herbal medicines, unlike conventional drugs comprise a complex mixture of

chemical constituents. In order to better understand the detection and handling of HDIs, an expansion on knowledge on phytochemicals in herbal medicines is essential. Presently in most cases, complete characterization of the bioactive compounds is not well defined, information on toxicity and adverse effects are insufficient. It is expected that standardization, including chemical fingerprinting would become potent tools for quality control of herbal medicines. However, because most of the available HDI information is based on individual case reports, animal studies and in vitro data, extensive research is required to confirm and assess the clinical significance of these 
potential interactions. HDIs may be under-reported and appropriate pharmacovigilance requires the collective responsibility of the patient, the health practitioner and researchers.

In this review, the pharmacokinetic (drug metabolizing enzymes and drug transporter systems) mechanisms have been considered to play a role in these interactions. There are reports on the inductive role of PXR as a nuclear receptor, however it is of importance to research into other receptors; constitutive androstane receptor (CAR), and vitamin D-binding receptor (VDR), as these may also play an integral role in the mechanism of inductive processes involved in HDIs. Future perspectives for the application of HDIs are in new drug development and use of herbal medicines as adjuvants to conventional drugs. They may also be used for their additive or synergistic effect when co-administered with modern medicine. This may require a decreased dose of the conventional drug, and possibly result to reduction in the manifestation of side effects. In particular, patients taking drugs with a narrow therapeutic index should be discouraged from using herbal products because of the ease of toxicity or ineffectiveness.

In summary, HDIs certainly occur and may have serious consequences. However because they are under-researched, present knowledge is incomplete. It is worth mentioning that the further research and more controlled clinical studies are needed to clarify and determine the underlying mechanisms for these altered drug effects. 


\section{References}

1. Sasidharan, S., et al., Extraction, isolation and characterization of bioactive compounds from plants' extracts. Afr J Tradit Complement Altern Med, 2011. 8(1): p. 1-10.

2. Calixto, J.B., Efficacy, safety, quality control, marketing and regulatory guidelines for herbal medicines (phytotherapeutic agents). Braz J Med Biol Res, 2000. 33(2): p. 179-89.

3. Mahady, G.B., Global harmonization of herbal health claims. J Nutr, 2001. 131(3s): p. 1120S-3S.

4. World Health Organization, Traditional medicine. 2008.

5. Tuffs, A., Three out of four Germans have used complementary or natural remedies. BMJ, 2002. 325(7371): p. 990.

6. Tachjian, A., V. Maria, and A. Jahangir, Use of herbal products and potential interactions in patients with cardiovascular diseases. J Am Coll Cardiol, 2010. 55(6): p. 515-25.

7. Komiya, A., A. Watanabe, and H. Fuse, Herbal medicine in Japan. Journal of Men's Health, 2011. 8(1): p. S15-S18.

8. Moschik, E.C., et al., Usage and attitudes of physicians in Japan concerning traditional Japanese medicine (kampo medicine): a descriptive evaluation of a representative questionnaire-based survey. Evid Based Complement Alternat Med, 2012. 2012: p. 139818.

9. Zhang, X., Regulatory Situation of Herbal Medicines: A worldwide Review. 1998: WHO Traditional Medicine Programme 45.

10. Walker, D.R. Report on the regulation of herbal medicines and practitioners. 2015.

11. Boyle, S.P., et al., Evaluation of quality control strategies in Scutellaria herbal medicines. J Pharm Biomed Anal, 2011. 54(5): p. 951-7.

12. Newman, D.J. and G.M. Cragg, Natural products as sources of new drugs over the 30 years from 1981 to 2010. J Nat Prod, 2012. 75(3): p. 311-35.

13. Lahlou, M., The Success of Natural Products in Drug Discovery. Pharmacology \& Pharmacy, 2013 4: p. 17-31.

14. Katiyar, C., et al., Drug discovery from plant sources: An integrated approach. Ayu, 2012. 33(1): p. 10-9.

15. Giacomini, K.M., et al., Membrane transporters in drug development. Nat Rev Drug Discov, 2010. 9(3): p. 215-36.

16. Muller, A.C. and I. Kanfer, Potential pharmacokinetic interactions between 
antiretrovirals and medicinal plants used as complementary and African traditional medicines. Biopharm Drug Dispos, 2011. 32(8): p. 458-70.

17. Guengerich, F.P., Cytochrome P450s and other enzymes in drug metabolism and toxicity. AAPS J, 2006. 8(1): p. E101-11.

18. Paine, M.F., et al., The human intestinal cytochrome P450 "pie". Drug Metab Dispos, 2006. 34(5): p. 880-6.

19. Kim, E., et al., Isolation and identification of intestinal CYP3A inhibitors from cranberry (Vaccinium macrocarpon) using human intestinal microsomes. Planta Med, 2011. 77(3): p. 265-70.

20. Jepson, R.G., G. Williams, and J.C. Craig, Cranberries for preventing urinary tract infections. Cochrane Database Syst Rev, 2012. 10: p. CD001321.

21. Uesawa, Y. and K. Mohri, Effects of cranberry juice on nifedipine pharmacokinetics in rats. J Pharm Pharmacol, 2006. 58(8): p. 1067-72.

22. Lilja, J.J., J.T. Backman, and P.J. Neuvonen, Effects of daily ingestion of cranberry juice on the pharmacokinetics of warfarin, tizanidine, and midazolam--probes of CYP2C9, CYP1A2, and CYP3A4. Clin Pharmacol Ther, 2007. 81(6): p. 833-9.

23. Ngo, N., et al., Identification of a cranberry juice product that inhibits enteric CYP3A-mediated first-pass metabolism in humans. Drug Metab Dispos, 2009. 37(3): p. 514-22.

24. Penzak, S.R., et al., Echinacea purpurea significantly induces cytochrome P450 $3 A$ activity but does not alter lopinavir-ritonavir exposure in healthy subjects. Pharmacotherapy, 2010. 30(8): p. 797-805.

25. Gorski, J.C., et al., The effect of echinacea (Echinacea purpurea root) on cytochrome P450 activity in vivo. Clin Pharmacol Ther, 2004. 75(1): p. 89-100.

26. Hansen, T.S. and O.G. Nilsen, In vitro CYP3A4 metabolism: inhibition by Echinacea purpurea and choice of substrate for the evaluation of herbal inhibition. Basic Clin Pharmacol Toxicol, 2008. 103(5): p. 445-9.

27. Eichhorn, T. and T. Efferth, P-glycoprotein and its inhibition in tumors by phytochemicals derived from Chinese herbs. J Ethnopharmacol, 2012. 141(2): p. 557-70.

28. Oga, E.F., et al., P-glycoprotein mediated efflux in Caco-2 cell monolayers: the influence of herbals on digoxin transport. Journal of Ethnopharmacology, 2012. 144(3): p. 612-617.

29. Li, Y., J. Lu, and J.W. Paxton, The role of ABC and SLC transporters in the pharmacokinetics of dietary and herbal phytochemicals and their interactions 
with xenobiotics. Curr Drug Metab, 2012. 13(5): p. 624-39.

30. Hermann, R. and O. von Richter, Clinical evidence of herbal drugs as perpetrators of pharmacokinetic drug interactions. Planta Med, 2012. 78(13): p. 1458-77.

31. Dahan, A. and H. Altman, Food-drug interaction: grapefruit juice augments drug bioavailability--mechanism, extent and relevance. Eur J Clin Nutr, 2004. 58(1): p. 1-9.

32. Bailey, D.G., et al., Grapefruit juice-drug interactions. Br J Clin Pharmacol, 1998. 46(2): p. 101-10.

33. Bailey, D.G., Fruit juice inhibition of uptake transport: a new type of food-drug interaction. Br J Clin Pharmacol, 2010. 70(5): p. 645-55.

34. Dresser, G.K. and D.G. Bailey, The effects of fruit juices on drug disposition: $a$ new model for drug interactions. Eur J Clin Invest, 2003. 33 Suppl 2: p. 10-6.

35. Fan, L., et al., The effect of herbal medicine baicalin on pharmacokinetics of rosuvastatin, substrate of organic anion-transporting polypeptide 1B1. Clin Pharmacol Ther, 2008. 83(3): p. 471-6.

36. Zhao, D., et al., Influence of rifampicin on the pharmacokinetics of salvianolic acid B may involve inhibition of organic anion transporting polypeptide (Oatp) mediated influx. Phytother Res, 2012. 26(1): p. 118-21.

37. Lin, C.C., et al., Evaluation of chinese-herbal-medicine-induced herb-drug interactions: focusing on organic anion transporter 1. Evid Based Complement Alternat Med, 2012. 2012: p. 967182.

38. Christians, U., V. Schmitz, and M. Haschke, Functional interactions between P-glycoprotein and CYP3A in drug metabolism. Expert Opin Drug Metab Toxicol, 2005. 1(4): p. 641-54.

39. Hellum, B.H., et al., Potent in vitro inhibition of CYP3A4 and P-glycoprotein by Rhodiola rosea. Planta Med, 2010. 76(4): p. 331-8.

40. Rahimi, R. and M. Abdollahi, An update on the ability of St. John's wort to affect the metabolism of other drugs. Expert Opin Drug Metab Toxicol, 2012. 8(6): p. 691-708.

41. Yu, C.P., et al., Quercetin and rutin reduced the bioavailability of cyclosporine from Neoral, an immunosuppressant, through activating P-glycoprotein and CYP 3A4. J Agric Food Chem, 2011. 59(9): p. 4644-8.

42. Markowitz, J.S., et al., Effect of St John's wort on drug metabolism by induction of cytochrome P450 3A4 enzyme. Jama, 2003. 290(11): p. 1500-4.

43. Willson, T.M. and S.A. Kliewer, PXR, CAR and drug metabolism. Nat Rev Drug 
Discov, 2002. 1(4): p. 259-66.

44. Lehmann, J.M., et al., The human orphan nuclear receptor PXR is activated by compounds that regulate CYP3A4 gene expression and cause drug interactions. J Clin Invest, 1998. 102(5): p. 1016-23.

45. Kliewer, S.A., B. Goodwin, and T.M. Willson, The nuclear pregnane $X$ receptor: a key regulator of xenobiotic metabolism. Endocr Rev, 2002. 23(5): p. 687-702.

46. Moore, L.B., et al., St. John's wort induces hepatic drug metabolism through activation of the pregnane X receptor. Proc Natl Acad Sci U S A, 2000. 97(13): p. 7500-2.

47. Geick, A., M. Eichelbaum, and O. Burk, Nuclear receptor response elements mediate induction of intestinal MDR1 by rifampin. J Biol Chem, 2001. 276(18): p. 14581-7.

48. Tien, E.S. and M. Negishi, Nuclear receptors CAR and PXR in the regulation of hepatic metabolism. Xenobiotica, 2006. 36(10-11): p. 1152-63.

49. Meijerman, I., J.H. Beijnen, and J.H. Schellens, Herb-drug interactions in oncology: focus on mechanisms of induction. Oncologist, 2006. 11(7): p. 742-52.

50. Gratus, C., et al., The use of herbal medicines by people with cancer: $a$ qualitative study. BMC Complement Altern Med, 2009. 9: p. 14.

51. He, S.M., et al., Effects of herbal products on the metabolism and transport of anticancer agents. Expert Opin Drug Metab Toxicol, 2010. 6(10): p. 1195-213.

52. Fong, H.H., Integration of herbal medicine into modern medical practices: issues and prospects. Integr Cancer Ther, 2002. 1(3): p. 287-93; discussion 293.

53. Smith, P., et al., The influence of St. John's wort on the pharmacokinetics and protein binding of imatinib mesylate. Pharmacotherapy, 2004. 24(11): p. 1508-14.

54. Frye, R.F., et al., Effect of St John's wort on imatinib mesylate pharmacokinetics. Clin Pharmacol Ther, 2004. 76(4): p. 323-9.

55. Hu, Z.P., et al., St. John's wort attenuates irinotecan-induced diarrhea via down-regulation of intestinal pro-inflammatory cytokines and inhibition of intestinal epithelial apoptosis. Toxicol Appl Pharmacol, 2006. 216(2): p. 225-37.

56. Mathijssen, R.H., et al., Effects of St. John's wort on irinotecan metabolism. J Natl Cancer Inst, 2002. 94(16): p. 1247-9.

57. Reif, S., et al., Effect of grapefruit juice intake on etoposide bioavailability. Eur J Clin Pharmacol, 2002. 58(7): p. 491-4.

58. Hasegawa, H., et al., Reversal of daunomycin and vinblastine resistance in multidrug-resistant P388 leukemia in vitro through enhanced cytotoxicity by 
triterpenoids. Planta Med, 1995. 61(5): p. 409-13.

59. Kim, S.W., et al., Reversal of P-glycoprotein-mediated multidrug resistance by ginsenoside Rg(3). Biochem Pharmacol, 2003. 65(1): p. 75-82.

60. Zhou, S., L.Y. Lim, and B. Chowbay, Herbal modulation of P-glycoprotein. Drug Metab Rev, 2004. 36(1): p. 57-104.

61. Hiraganahalli, B.D., et al., Hepatoprotective and antioxidant activity of standardized herbal extracts. Pharmacogn Mag, 2012. 8(30): p. 116-23.

62. Olaku, O. and J.D. White, Herbal therapy use by cancer patients: a literature review on case reports. Eur J Cancer, 2011. 47(4): p. 508-14.

63. Lee, S.A., et al., Anti-HIV-1 efficacy of extracts from medicinal plants. J Microbiol, 2010. 48(2): p. 249-52.

64. Liu, J., The use of herbal medicines in early drug development for the treatment of HIV infections and AIDS. Expert Opin Investig Drugs, 2007. 16(9): p. 1355-64.

65. Bepe, N., et al., The impact of herbal remedies on adverse effects and quality of life in HIV-infected individuals on antiretroviral therapy. J Infect Dev Ctries, 2011. 5(1): p. 48-53.

66. Muller, A.C., et al., Interactions between phytochemical components of Sutherlandia frutescens and the antiretroviral, atazanavir in vitro: implications for absorption and metabolism. J Pharm Pharm Sci, 2012. 15(2): p. 221-33.

67. Patel, J., et al., In vitro interaction of the HIV protease inhibitor ritonavir with herbal constituents: changes in P-gp and CYP3A4 activity. Am J Ther, 2004. 11(4): p. 262-77.

68. Piscitelli, S.C., et al., Indinavir concentrations and St John's wort. Lancet, 2000. 355(9203): p. 547-8.

69. Foster, B.C., et al., An in vitro evaluation of human cytochrome P450 3A4 and P-glycoprotein inhibition by garlic. J Pharm Pharm Sci, 2001. 4(2): p. 176-84.

70. Hajda, J., et al., Garlic extract induces intestinal P-glycoprotein, but exhibits no effect on intestinal and hepatic CYP3A4 in humans. Eur J Pharm Sci, 2010. 41(5): p. 729-35.

71. Piscitelli, S.C., et al., The effect of garlic supplements on the pharmacokinetics of saquinavir. Clin Infect Dis, 2002. 34(2): p. 234-8.

72. Gallicano, K., B. Foster, and S. Choudhri, Effect of short-term administration of garlic supplements on single-dose ritonavir pharmacokinetics in healthy volunteers. Br J Clin Pharmacol, 2003. 55(2): p. 199-202.

73. Kasibhatta, R. and M.U. Naidu, Influence of piperine on the pharmacokinetics of 
nevirapine under fasting conditions: a randomised, crossover, placebo-controlled study. Drugs R D, 2007. 8(6): p. 383-91.

74. Bhardwaj, R.K., et al., Piperine, a major constituent of black pepper, inhibits human P-glycoprotein and CYP3A4. J Pharmacol Exp Ther, 2002. 302(2): p. 645-50.

75. Asase, A., G.A. Akwetey, and D.G. Achel, Ethnopharmacological use of herbal remedies for the treatment of malaria in the Dangme West District of Ghana. J Ethnopharmacol, 2010. 129(3): p. 367-76.

76. Wells, T.N., Natural products as starting points for future anti-malarial therapies: going back to our roots? Malar J, 2011. 10 Suppl 1: p. S3.

77. Oga, E.F., S. Sekine, and T. Horie, Ex vivo and in vivo investigations of the effects of extracts of Vernonia amygdalina, Carica papaya and Tapinanthus sessilifolius on digoxin transport and pharmacokinetics: assessing the significance on rat intestinal P-glycoprotein efflux. Drug Metab Pharmacokinet, 2013. 28(4): p. 314-20.

78. Onaku, L.O., et al., Antagonistic antimalarial properties of pawpaw leaf aqueous extract in combination with artesunic acid in Plasmodium berghei-infected mice. J Vector Borne Dis, 2011. 48(2): p. 96-100.

79. Mohd Ridzuan, M.A., et al., Eurycoma longifolia extract-artemisinin combination: parasitemia suppression of Plasmodium yoelii-infected mice. Trop Biomed, 2007. 24(1): p. 111-8.

80. Mohd Ridzuan, M.A., et al., Antimalarial properties of Goniothalamin in combination with chloroquine against Plasmodium yoelii and Plasmodium berghei growth in mice. Trop Biomed, 2006. 23(2): p. 140-6.

81. Nandakumar, D.N., et al., Curcumin-artemisinin combination therapy for malaria. Antimicrob Agents Chemother, 2006. 50(5): p. 1859-60.

82. Iwalokun, B.A., Enhanced antimalarial effects of chloroquine by aqueous Vernonia amygdalina leaf extract in mice infected with chloroquine resistant and sensitive Plasmodium berghei strains. Afr Health Sci, 2008. 8(1): p. 25-35.

83. Tepongning, R.N., et al., Potential of a Khaya ivorensis -Alstonia boonei extract combination as antimalarial prophylactic remedy. J Ethnopharmacol, 2011. 137(1): p. 743-51.

84. Kim, W.R., et al., Burden of liver disease in the United States: summary of a workshop. Hepatology, 2002. 36(1): p. 227-42.

85. Verma, S. and P.J. Thuluvath, Complementary and alternative medicine in hepatology: review of the evidence of efficacy. Clin Gastroenterol Hepatol, 2007. 
5(4): p. 408-16.

86. Giese, L.A., Milk thistle and the treatment of hepatitis. Gastroenterol Nurs, 2001. 24(2): p. 95-7.

87. Flora, K., et al., Milk thistle (Silybum marianum) for the therapy of liver disease. Am J Gastroenterol, 1998. 93(2): p. 139-43.

88. Tamayo, C. and S. Diamond, Review of clinical trials evaluating safety and efficacy of milk thistle (Silybum marianum [L.] Gaertn.). Integr Cancer Ther, 2007. 6(2): p. 146-57.

89. Gurley, B.J., et al., Effect of milk thistle (Silybum marianum) and black cohosh (Cimicifuga racemosa) supplementation on digoxin pharmacokinetics in humans. Drug Metab Dispos, 2006. 34(1): p. 69-74.

90. Brantley, S.J., et al., Two flavonolignans from milk thistle (Silybum marianum) inhibit CYP2C9-mediated warfarin metabolism at clinically achievable concentrations. J Pharmacol Exp Ther, 2010. 332(3): p. 1081-7.

91. Kumada, H., Long-term treatment of chronic hepatitis $C$ with glycyrrhizin [stronger neo-minophagen C (SNMC)] for preventing liver cirrhosis and hepatocellular carcinoma. Oncology, 2002. 62 Suppl 1: p. 94-100.

92. Chen, M.F., et al., Effect of oral administration of glycyrrhizin on the pharmacokinetics of prednisolone. Endocrinol Jpn, 1991. 38(2): p. 167-74.

93. Methlie, P., et al., Grapefruit juice and licorice increase cortisol availability in patients with Addison's disease. Eur J Endocrinol, 2011. 165(5): p. 761-9.

94. Roy, A., et al., Use of herbal remedies and adherence to inhaled corticosteroids among inner-city asthmatic patients. Ann Allergy Asthma Immunol, 2010. 104(2): p. 132-8.

95. Lee, D.K., et al., Butterbur, a herbal remedy, confers complementary anti-inflammatory activity in asthmatic patients receiving inhaled corticosteroids. Clin Exp Allergy, 2004. 34(1): p. 110-4.

96. Nebel, A., et al., Potential metabolic interaction between St. John's wort and theophylline. Ann Pharmacother, 1999. 33(4): p. 502.

97. Morimoto, T., et al., Effect of St. John's wort on the pharmacokinetics of theophylline in healthy volunteers. J Clin Pharmacol, 2004. 44(1): p. 95-101.

98. Wang, Z., et al., Effect of St John's wort on the pharmacokinetics of fexofenadine. Clin Pharmacol Ther, 2002. 71(6): p. 414-20.

99. Dresser, G.K., et al., Coordinate induction of both cytochrome P4503A and MDR1 by St John's wort in healthy subjects. Clin Pharmacol Ther, 2003. 73(1): p. 41-50. 
100. Shelton, R.C., St John's wort (Hypericum perforatum) in major depression. J Clin Psychiatry, 2009. 70 Suppl 5: p. 23-7.

101. Linde, K., et al., St John's wort for depression--an overview and meta-analysis of randomised clinical trials. BMJ, 1996. 313(7052): p. 253-8.

102. Johne, A., et al., Pharmacokinetic interaction of digoxin with an herbal extract from St John's wort (Hypericum perforatum). Clin Pharmacol Ther, 1999. 66(4): p. 338-45.

103. Durr, D., et al., St John's Wort induces intestinal P-glycoprotein/MDR1 and intestinal and hepatic CYP3A4. Clin Pharmacol Ther, 2000. 68(6): p. 598-604.

104. Malati, C.Y., et al., Influence of Panax ginseng on cytochrome P450 (CYP)3A and P-glycoprotein (P-gp) activity in healthy participants. J Clin Pharmacol, 2012. 52(6): p. 932-9.

105. Yuan, C.S., et al., Brief communication: American ginseng reduces warfarin's effect in healthy patients: a randomized, controlled Trial. Ann Intern Med, 2004. 141(1): p. 23-7.

106. Chow, H.H., et al., Effects of repeated green tea catechin administration on human cytochrome P450 activity. Cancer Epidemiol Biomarkers Prev, 2006. 15(12): p. 2473-6.

107. Donovan, J.L., et al., Green tea (Camellia sinensis) extract does not alter cytochrome p450 3A4 or 2D6 activity in healthy volunteers. Drug Metab Dispos, 2004. 32(9): p. 906-8.

108. Molto, J., et al., Herb-drug interaction between Echinacea purpurea and darunavir-ritonavir in HIV-infected patients. Antimicrob Agents Chemother, 2011. 55(1): p. 326-30.

109. Barnes, J., et al., Echinacea species (Echinacea angustifolia (DC.) Hell., Echinacea pallida (Nutt.) Nutt.,Echinacea purpurea (L.) Moench): a review of their chemistry, pharmacology and clinical properties. J Pharm Pharmacol, 2005. 57(8): p. 929-54.

110. Fan, L., et al., Effects of Ginkgo biloba extract ingestion on the pharmacokinetics of talinolol in healthy Chinese volunteers. Ann Pharmacother, 2009. 43(5): p. 944-9.

111. Fan, L., et al., Effect of Schisandra chinensis extract and Ginkgo biloba extract on the pharmacokinetics of talinolol in healthy volunteers. Xenobiotica, 2009. 39(3): p. 249-54.

112. Wang, Y., J. Cao, and S. Zeng, Involvement of P-glycoprotein in regulating cellular levels of Ginkgo flavonols: quercetin, kaempferol, and isorhamnetin. J 
Pharm Pharmacol, 2005. 57(6): p. 751-8.

113. Uchida, S., et al., Effects of Ginkgo biloba extract on pharmacokinetics and pharmacodynamics of tolbutamide and midazolam in healthy volunteers. J Clin Pharmacol, 2006. 46(11): p. 1290-8.

114. Robertson, S.M., et al., Effect of Ginkgo biloba extract on lopinavir, midazolam and fexofenadine pharmacokinetics in healthy subjects. Curr Med Res Opin, 2008. 24(2): p. 591-9.

115. Singh, D., R. Gupta, and S.A. Saraf, Herbs-are they safe enough? an overview. Crit Rev Food Sci Nutr, 2012. 52(10): p. 876-98.

116. Debelle, F.D., J.L. Vanherweghem, and J.L. Nortier, Aristolochic acid nephropathy: a worldwide problem. Kidney Int, 2008. 74(2): p. 158-69.

117. Lietman, P.S., Herbal medicine development: a plea for a rigorous scientific foundation. Am J Ther, 2012. 19(5): p. 351-6.

118. Shetti, S., et al., Pharmacovigilance of herbal medicines: Current state and future directions. Pharmacogn Mag, 2011. 7(25): p. 69-73.

119. Skalli, S. and R. Soulaymani Safety monitoring of herb-drug interactions: a component of pharmacovigilance. Drug Saf, 2012. 35(10): p. 785-91.

120. Barnes, J., Pharmacovigilance of herbal medicines : a UK perspective. Drug Saf, 2003. 26(12): p. 829-51.

121. World Health Organization, The Importance of Pharmacovigilance - Safety Monitoring of Medicinal Products. 2002, Uppsala, Sweden: Uppsala Monitoring Centre, WHO Collaborating Centre for International Drug Monitoring. 52.

122. Wang, C.C., et al., Safety evaluation of commonly used Chinese herbal medicines during pregnancy in mice. Hum Reprod, 2012. 27(8): p. 2448-56.

123. Steenkamp, V. and M.J. Stewart, Nephrotoxicity associated with exposure to plant toxins, with particular reference to Africa. Ther Drug Monit, 2005. 27(3): p. 270-7.

124. Gulumian, M. and K. Savolainen, Toxicological issues in developed and developing countries: the difference is in approach and not in content. Hum Exp Toxicol, 2012. 31(3): p. 205-6.

125. Avila, D., K. Helmcke, and M. Aschner, The Caenorhabiditis elegans model as a reliable tool in neurotoxicology. Hum Exp Toxicol, 2012. 31(3): p. 236-43.

126. Melchart, D., et al., Polysaccharides isolated from Echinacea purpurea herbal cell cultures to counteract undesired effects of chemotherapy--a pilot study. Phytother Res, 2002. 16(2): p. 138-42.

127. Bossaer, J.B. and B.L. Odle, Probable etoposide interaction with Echinacea. J 
Diet Suppl, 2012. 9(2): p. 90-5.

128. de Maat, M.M., et al., Drug interaction between St John's wort and nevirapine. Aids, 2001. 15(3): p. 420-1.

129. Holodniy, M., et al., A double blind, randomized, placebo-controlled phase II study to assess the safety and efficacy of orally administered SP-303 for the symptomatic treatment of diarrhea in patients with AIDS. Am J Gastroenterol, 1999. 94(11): p. 3267-73.

130. Smith, M., K. Lin, and Y. Zheng, An open trial of nifedipine-herb interactions: Nifedipine with St. John's wort, ginseng or Ginkgo biloba. Abstract PIII-89. Clin Pharmacol Ther, 2001. 69(2): p. P1-128.

131. Sugimoto, K., et al., Different effects of St John's wort on the pharmacokinetics of simvastatin and pravastatin. Clin Pharmacol Ther, 2001. 70(6): p. 518-24.

132. Gurley, B.J., et al., In vivo effects of goldenseal, kava kava, black cohosh, and valerian on human cytochrome P450 1A2, 2D6, 2E1, and 3A4/5 phenotypes. Clin Pharmacol Ther, 2005. 77(5): p. 415-26.

133. Juan, H., et al., Unexpected effect of concomitantly administered curcumin on the pharmacokinetics of talinolol in healthy Chinese volunteers. Eur J Clin Pharmacol, 2007. 63(7): p. 663-8.

134. Chen, X.W., et al., Clinical herbal interactions with conventional drugs: from molecules to maladies. Curr Med Chem, 2011. 18(31): p. 4836-50.

135. Glaeser, H., et al., Intestinal drug transporter expression and the impact of grapefruit juice in humans. Clin Pharmacol Ther, 2007. 81(3): p. 362-70.

136. Dresser, G.K., et al., Fruit juices inhibit organic anion transporting polypeptide-mediated drug uptake to decrease the oral availability of fexofenadine. Clin Pharmacol Ther, 2002. 71(1): p. 11-20.

137. Henderson, L., et al., St John's wort (Hypericum perforatum): drug interactions and clinical outcomes. Br J Clin Pharmacol, 2002. 54(4): p. 349-56.

138. Chung, K.F., et al., Effect of a ginkgolide mixture (BN 52063) in antagonising skin and platelet responses to platelet activating factor in man. Lancet, 1987. 1(8527): p. 248-51.

139. Rowin, J. and S.L. Lewis, Spontaneous bilateral subdural hematomas associated with chronic Ginkgo biloba ingestion. Neurology, 1996. 46(6): p. 1775-6.

140. Meisel, C., A. Johne, and I. Roots, Fatal intracerebral mass bleeding associated with Ginkgo biloba and ibuprofen. Atherosclerosis, 2003. 167(2): p. 367.

141. Yue, Q.Y., C. Bergquist, and B. Gerden, Safety of St John's wort (Hypericum 
perforatum). Lancet, 2000. 355(9203): p. 576-7.

142. Bauer, S., et al., Alterations in cyclosporin A pharmacokinetics and metabolism during treatment with St John's wort in renal transplant patients. Br J Clin Pharmacol, 2003. 55(2): p. 203-11.

143. Mai, I., et al., Impact of St John's wort treatment on the pharmacokinetics of tacrolimus and mycophenolic acid in renal transplant patients. Nephrol Dial Transplant, 2003. 18(4): p. 819-22.

144. Alemdaroglu, N.C., et al., Influence of green and black tea on folic acid pharmacokinetics in healthy volunteers: potential risk of diminished folic acid bioavailability. Biopharm Drug Dispos, 2008. 29(6): p. 335-48.

145. Tuntipopipat, S., et al., Chili, but not turmeric, inhibits iron absorption in young women from an iron-fortified composite meal. J Nutr, 2006. 136(12): p. 2970-4.

146. Di Marco, M.P., et al., The effect of grapefruit juice and seville orange juice on the pharmacokinetics of dextromethorphan: the role of gut CYP3A and P-glycoprotein. Life Sci, 2002. 71(10): p. 1149-60.

147. Hall, S.D., et al., The interaction between St John's wort and an oral contraceptive. Clin Pharmacol Ther, 2003. 74(6): p. 525-35.

148. Yin, O.Q., et al., Pharmacogenetics and herb-drug interactions: experience with Ginkgo biloba and omeprazole. Pharmacogenetics, 2004. 14(12): p. 841-50. 
Table 1. Clinically relevant herb-drug interactions

\begin{tabular}{|c|c|c|c|c|}
\hline Disorder & $\begin{array}{l}\text { Conventional } \\
\text { drug }\end{array}$ & Herbal medicine & Effect in human subjects & Ref \\
\hline \multirow[t]{5}{*}{ Cancer } & Imatinib & $\begin{array}{c}\text { St. John's wort } \\
\text { (Hypericum perforatum) }\end{array}$ & $\begin{array}{c}43 \% \uparrow \text { in imatinib clearance } \\
\downarrow \text { of up to } 32 \% \text { mean area under the concentration-time } \\
\text { curve } \\
\text { significantly } \downarrow \mathrm{C}_{\max } \text { and half-life }\end{array}$ & {$[49,53,54]$} \\
\hline & Irinotecan & St John's wort & $\begin{array}{c}42 \% \downarrow \text { in plasma levels of the active metabolite of } \\
\text { irinotecan }\end{array}$ & {$[49,55,56]$} \\
\hline & $\begin{array}{c}\text { Etoposide } \\
\text { Leucovirin } \\
\text { 5-fluoro uracil }\end{array}$ & $\begin{array}{c}\text { Echinacea } \\
\text { (Echinacea purpurea) }\end{array}$ & $\begin{array}{l}\text { Median number of leucocytes } \uparrow \text { significantly in comparison to } \\
\text { the control group }\end{array}$ & [126] \\
\hline & Etoposide & Echinacea & $\begin{array}{c}\text { One case reporting a possible interaction between etoposide, } \\
\text { and echinacea which resulted in trombocytopenia requiring a } \\
\text { platelet transfusion }\end{array}$ & [127] \\
\hline & & Ginkgo (Ginkgo biloba) & & \\
\hline \multirow[t]{4}{*}{ HIV/AIDS } & Saquinavir & Garlic (Allium sativum) & 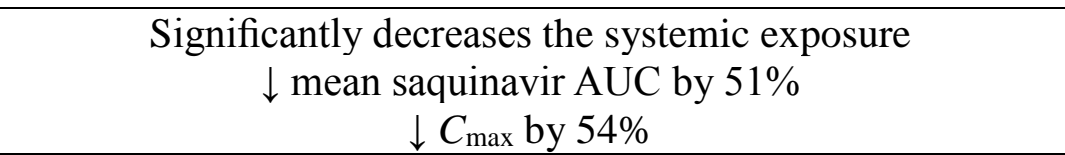 & [71] \\
\hline & Indinavir & St. John’s wort & $\begin{array}{l}\quad \downarrow \mathrm{AUC}_{0-8} \text { of indinavir decreased by a mean of } 57 \% \\
\quad 49-99 \% \text { in concentration } 8 \mathrm{hr} \text { post-dosing } \\
\downarrow \text { in the mean } \mathrm{C}_{\max } \text { of indinavir from } 12 \cdot 3 \mu \mathrm{g} / \mathrm{mL} \text { to } 8 \cdot 9 \mu \mathrm{g} / \mathrm{mL}\end{array}$ & [68] \\
\hline & Nevirapine & St. John’s wort & Clearance of nevirapine $\uparrow$ by $35 \%{ }^{\#}$ & [128] \\
\hline & $\begin{array}{l}\text { Protease } \\
\text { inhibitors }\end{array}$ & $\begin{array}{l}\text { SP-303 (an extract of } \\
\text { Croton lechler) }\end{array}$ & $\begin{array}{l}\text { Significant reduction of stool weight and stool frequency in } \\
\text { AIDS patients who had diarrhea }\end{array}$ & [129] \\
\hline \multirow{4}{*}{$\begin{array}{l}\text { Cardiovascular } \\
\text { disease }\end{array}$} & Nifedipine & Ginseng (Panax ginseng) & $\uparrow$ Cmax of nifedipine by $29 \%$ & {$[130]$} \\
\hline & Simvastatin & St. John's wort & $52 \% \downarrow$ in AUC and $28 \% \downarrow$ in Cmax $\#$ & [131] \\
\hline & Debrisoquin & $\begin{array}{c}\text { Goldenseal } \\
\text { (Hydrastis canadensis) }\end{array}$ & Goldenseal strongly inhibited CYP2D6 activity & [132] \\
\hline & Talinolol & Curcumin & The consumption of curcumin $\downarrow$ AUC and $\mathrm{C}_{\max }$ of talinolol & [133] \\
\hline
\end{tabular}




\begin{tabular}{|c|c|c|c|c|}
\hline & & (Curcuma longa) & & \\
\hline & Digoxin & St John’s wort & $\begin{array}{l}10 \text { days of treatment with St John’s wort } \downarrow \text { digoxin } \mathrm{AUC}_{(0-24)} \\
\text { by } 25 \%\end{array}$ & [102] \\
\hline Diabetes & Chlorpropamide & Garlic & $\uparrow$ hypoglycaemia & {$[134]$} \\
\hline \multirow[t]{4}{*}{ Asthma and allergy } & Fexofenadine & St. John’s wort & $\begin{array}{c}\text { Single dose significantly } \uparrow \text { Cp (max) of fexofenadine by } 45 \% \\
\text { and significantly } \downarrow \text { oral clearance by } 20 \% * \\
\text { Long-term dose significantly } \downarrow \text { Cp (max) of fexofenadine by } \\
35 \% \text { and significantly } \uparrow \text { oral clearance by } 47 \% \text { ฯ } \\
\end{array}$ & {$[98]$} \\
\hline & Fexofenadine & $\begin{array}{l}\text { Grape fruit juice } \\
\text { ( Citrus paradisi) }\end{array}$ & $\begin{array}{l}\text { Consumption of grapefruit juice concomitantly or } 2 \mathrm{~h} \text { before } \\
\text { fexofenadine administration was associated with } \downarrow \text { oral fexofenadine } \\
\text { plasma exposure }\end{array}$ & [135] \\
\hline & Fexofenadine & $\begin{array}{l}\text { Orange juice } \\
\text { ( Citrus sinensis) }\end{array}$ & $\begin{array}{c}\text { Orange juice } \downarrow \text { the AUC, }\left(\mathrm{C}_{\max }\right) \text { and the urinary excretion } \\
\text { values fexofenadine }\end{array}$ & [136] \\
\hline & Thiazides & Gingko & $\uparrow$ blood pressure when combined with thiazide diuretics & {$[134]$} \\
\hline \multirow[t]{4}{*}{ Depression } & Midazolam & Echinacea & $\begin{array}{l}\text { Significantly } \uparrow \text { systemic clearance of midazolam by } 34 \% \text {, } \\
\text { Significantly } \downarrow \text { midazolam AUC by } 23 \% \\
\text { Significantly } \uparrow \text { oral availability of midazolam after echinacea } \\
\text { dosing }\end{array}$ & {$[25]$} \\
\hline & Midazolam & Goldenseal & Goldenseal strongly inhibited CYP3A4/5 activity & [132] \\
\hline & Alprazolam & St. John's wort & Significantly $\downarrow$ alprazolam AUC by $54 \%$ & {$[42]$} \\
\hline & $\begin{array}{l}\text { SSRIs } \\
\text { (Citalopram, } \\
\text { fluoxetine, } \\
\text { fluvoxamine, } \\
\text { paroxetine, } \\
\text { sertraline) }\end{array}$ & St. John's wort & $\begin{array}{l}\text { Increased serotonergic effects with risk of increased incidence } \\
\text { of adverse reactions }\end{array}$ & [137] \\
\hline \multirow{2}{*}{$\begin{array}{l}\text { Deep vein } \\
\text { thrombosis }\end{array}$} & $\begin{array}{l}\text { Warfarin } \\
\text { Ibuprofen }\end{array}$ & Ginkgo & $\begin{array}{c}\text { Potently inhibits platelet activating factor-mediated platelet } \\
\text { aggregation } \\
\uparrow \text { the fluididity of blood }\end{array}$ & [138-140] \\
\hline & Warfarin & Garlic & $\begin{array}{l}\text { Garlic } \uparrow \text { clotting time and international normalized ratio (INR) } \\
\text { of warfarin }\end{array}$ & [134] \\
\hline
\end{tabular}




\begin{tabular}{|c|c|c|c|c|}
\hline & Warfarin & St John's wort & $\downarrow$ anticoagulant effect of warfarin & [141] \\
\hline & Warfarin & Ginseng & $\begin{array}{c}\text { Ginseng significantly } \downarrow \text { warfarin’s anti-coagulant effect by } \downarrow \\
\text { the international normalized ratio (INR) and reducing plasma } \\
\text { warfarin levels. }\end{array}$ & [105] \\
\hline CNS stimulation & Caffeine & Echinacea & Echinacea dosing significantly $\downarrow$ the oral clearance of caffeine & [25] \\
\hline \multirow{2}{*}{ Immunosuppression } & Cyclosporin A & \multirow{2}{*}{ St. John’s wort } & $46 \% \downarrow$ in AUC and $42 \% \downarrow$ in $\operatorname{Cmax}^{\#, q}$ & [142] \\
\hline & Tacrolimus & & $\downarrow$ in AUC by $58 \%{ }^{\#, q}$ & [143] \\
\hline $\begin{array}{c}\text { Vitamin } \\
\text { supplementation }\end{array}$ & Folic acid & $\begin{array}{c}\text { Green tea } \\
\text { (Camellia sinensis) }\end{array}$ & Green and black tea extracts $\downarrow$ folic acid bioavailability & [144] \\
\hline $\begin{array}{c}\text { Mineral } \\
\text { supplementation }\end{array}$ & Iron & $\begin{array}{c}\text { Chilli } \\
\text { (Capsicum annuum) }\end{array}$ & Inhibition of iron absorption in young women & [145] \\
\hline Antitussive & Dextromethorphan & $\begin{array}{l}\text { Citrus aurantium } \\
\text { Citrus paradisi }\end{array}$ & $\begin{array}{l}\text { Bioavailability of dextromethorphan increased significantly } \\
\text { with grapefruit and seville orange juice*, }\end{array}$ & [146] \\
\hline \multirow{2}{*}{ Oral Contraception } & Norethindrone & St John’s wort & $\begin{array}{c}\text { Significant } \uparrow \text { in oral clearance of norethindrone, } \uparrow \text { risk of } \\
\text { unintended pregnancy and breakthrough bleeding }\end{array}$ & [147] \\
\hline & Ethinyl estradiol & St John’s wort & $\begin{array}{c}\text { Significant } \downarrow \text { in the half-life of ethinyl estradiol, } \uparrow \text { risk of } \\
\text { unintended pregnancy and breakthrough bleeding }\end{array}$ & [147] \\
\hline Headaches & $\begin{array}{c}\text { Triptans } \\
\text { (sumatriptan, } \\
\text { naratriptan, } \\
\text { rizatriptan, } \\
\text { zolmitriptan) }\end{array}$ & St John's wort & $\begin{array}{l}\text { Increased serotonergic effects with risk of increased incidence } \\
\text { of adverse reactions }\end{array}$ & [137] \\
\hline Ulcers & Omeprazole & Gingko & $\begin{array}{c}\text { Significant } \downarrow \text { in plasma concentrations of omeprazole and } \\
\text { omeprazole sulphone and significant } \uparrow \text { of } \\
\text { 5-hydroxyomeprazole }\end{array}$ & [148] \\
\hline
\end{tabular}

*, Proposed mechanism, inhibition of intestinal p-gp

\#, Proposed mechanism, induction of CYP 3A4
ॠ, Proposed mechanism, induction of p-gp

$\S$, Proposed mechanism, inhibition of intestinal p-gp 


\section{Figure Legends}

\section{Figure 1}

Illustration of the main mechanisms of herb-drug interactions with some examples.

\section{Figure 2}

Transporter expression in the main organs influencing drug disposition

\section{Figure 3}

Mean concentration-time profile of indinavir alone (solid line) and with concomitant St John's wort (dotted line), showing a large reduction in indinavir concentrations by concomitant St John's wort. In the study, fasting participants received indinavir $800 \mathrm{mg}$ orally. They then received two more doses at $8 \mathrm{~h}$ intervals to achieve steady-state. On the morning of day 2, an $800 \mathrm{mg}$ dose was given. On day 3, participants began treatment with St John's wort (300 mg three times daily) for 14 days. Piscitelli et al., 2000. (Reproduced with permission from Elsevier)

\section{Figure 4}

Concentration-time profiles for midazolam $( \pm$ SEM) before and after Panax ginseng administration. In this study, the pparticipants were administered a single 8-mg oral dose of midazolam syrup. They then began taking $P$ ginseng at a dose of $500 \mathrm{mg}$ twice daily for 28 days. On day 28 of $P$ ginseng administration, participants returned to the clinic for a repeat dose of midazolam. Malati et al., 2012. (Reproduced with permission from John Wiley \& Sons, Inc) 